\title{
BIOMEDICAL STUDY OF DEMOGRAPHICS AND CLINICAL FEATURES OF LiCHEN PLANOPILARIS AMONg THE IRANIAN POPULATION
}

\author{
Maryamsadat Nejadghaderi ${ }^{1}$, Ashkan Tashk $^{2}$, Parvin Mansouri ${ }^{1}$ \\ and Zahra Safaei Naraghi ${ }^{1}$ \\ ${ }^{1}$ Tehran University of Medical Sciences (TUMS), Tehran, Iran \\ ${ }^{2}$ Applied AI and Data Science Group, Mærsk McKinney Møller Institute \\ (MMMI), University of Southern Denmark (SDU), Odense, Denmark
}

\begin{abstract}
Introduction: The demographic of Lichen PlanoPilaris (LPP) among the Iranian population is unknown. The aim of this study is to describe the clinical, demographic, and histopathologic findings of lichen planopilaris in the Iranian population.

Method: In this cross-sectional study, all the patients with Lichen planopilaris were referred to the dermatology clinic of Imam Khomeini hospital from 2013 to 2015. Their demographic characteristics, drug histories, onset of disease, and family histories were obtained by written questionnaire. Additionally, this study employed SPSS v.20 as the statistical analysis software.

Results: One hundred patients were enrolled in this study. With an average age of 47.11 years, $78 \%$ of the patients were female, and 50 of these were housewives. The patients included were often from Tehran with Fars ethnicity. Among these patients, 7 had alopecia areata skin disease, and 10 of them suffered from thyroid disease. Most of the histopathology samples collected from these biopsies revealed degeneration of the basal layer of the follicular structure, perifollicular fibrosis, inflammatory cells, and atrophy of the pilosebaceous structures.
\end{abstract}

Conclusion: Both the age spectrum and the disease distribution of LPP among the Iranian population were very diverse when compared to previous studies.

\section{KEYWORDS}

Lichen PlanoPilaris (LPP), Epidemiologic, Demographics, Clinical Features, histology.

\section{INTRODUCTION}

Lichen planopilaris (LPP) is a follicular form of lichen planus, an autoimmune disease, which frequently presents as primary cicatricial alopecia and a rare inflammatory scalp disorder [1-4]. Lichen planopilaris is clinically characterized as hair loss, hyperkeratosis and perifollicular erythema [2-5]. The age of onset of LPP is between 40 and 60 years, and women are more affected by it than men $[1,6]$.

The incidence, prevalence, and physiopathology of LPP is unclear and unknown [7-9]. North American tertiary hair research centers recommend that patients with existing lichen planopilaris be admitted to their centers to evaluate their demographic, epidemiologic, and clinical features David C. Wyld et al. (Eds): SAIM, SIPM, ACSIT, FCST, ICITE - 2020 
[10]. Demographic and Epidemiologic data on LPP in Iranian people are limited. The aim of this study is to describe the clinical, demographic, and histopathologic findings of lichen planopilaris among the Iranian population.

\section{MATERIAL AND MeThodS}

This cross-sectional study was conducted on patients with the diagnosis of lichen planopilaris who were referred to the dermatology clinic of Tehran Imam Khomeini hospital affiliated by Tehran University of Medical Sciences (TUMS) between Sep 2013 and Sep 2015.

Lichen planopilaris was diagnosed by collecting histological evidence, dermatological examination, and clinical diagnosis. The inclusive criteria were lymphocytic cicatricial alopecia with perifollicular infiltrate. Patients without the histological confirmation were excluded.

Information about demographic characteristics, drug history, onset of disease, family history, the presenting complaint (signs and symptoms), hepatitis vaccination, consumption of gold or Dental amalgam, were obtained by written questionnaire.

This study was approved by the research Ethics Committee of the Tehran University of Medical Sciences, and the participants gave their voluntary participation consent at this study.

\section{RESUlts}

The whole statistical analysis related to this study are done by the means of SPSS v.20 (SPSS Inc, Chicago, IL, USA).

A total number of 118 patients were enrolled in this study, and of these 100 had the inclusive criteria and therefore were included in this study. Of these 100 patients, 78 (78\%) were women and $22 \%$ were men. The average age was $47.11 \pm 13.10$ years, with the youngest patient being 14 and the oldest 82 . Ninety percent of the patients were married. The age of onset of disease was between 7 to 70 years, and the average age was $41.19 \pm 13.03$.

Table 1. Demographic characteristics

\begin{tabular}{|c|l|l|}
\hline title & \multicolumn{1}{|c|}{ characteristic } & \multicolumn{1}{|c|}{$\mathbf{N}(\%)$} \\
\hline \multirow{4}{*}{ Smoking } & Yes & $4(4 \%)$ \\
\cline { 2 - 3 } & No & $96(96 \%)$ \\
\hline \multirow{5}{*}{ Ethnicity } & Fars & $88(88 \%)$ \\
\cline { 2 - 3 } & Turkic & $8(8 \%)$ \\
\cline { 2 - 3 } & Kurd & $3(3 \%)$ \\
\cline { 2 - 3 } & Lori & $1(1 \%)$ \\
\hline \multirow{5}{*}{ Domicile } & Low literacy & $12(12 \%)$ \\
\cline { 2 - 3 } & Diploma & $48(48 \%)$ \\
\cline { 2 - 3 } & Bachelor & $30(30 \%)$ \\
\cline { 2 - 3 } & Master degree & $8(8 \%)$ \\
\cline { 2 - 3 } & Doctorate degree & $2(2 \%)$ \\
\hline \multirow{5}{*}{ Occupation } & Tehran & $73(73 \%)$ \\
\cline { 2 - 3 } & Other city & $27(27 \%)$ \\
\cline { 2 - 3 } & Housekeeper & $50(50 \%)$ \\
\cline { 2 - 3 } & Employee & $19(19 \%)$ \\
\cline { 2 - 3 } & Self-employed & $12(12 \%)$ \\
\cline { 2 - 3 } & Student & $4(4 \%)$ \\
\cline { 2 - 3 } & Unemployed & $7(7 \%)$ \\
\cline { 2 - 3 } & Another job & $8(8 \%)$ \\
\hline
\end{tabular}


Fifty-one percent of the present patients had a history of stress, and 15\% of the patients had a long-term duration history to sun exposure. Two of the patients had a history of radiation therapy (RT). In $19 \%$ of the patients, there was a positive history of LPP. Twenty-one percent of the patients had received a hepatitis vaccination before the onset of LPP, and none of them had a history of infectious disease. The Signs, symptoms, and medical history of the participating patients in this research are presented in table 2.

Table 2. Medical history

\begin{tabular}{|c|c|c|}
\hline Title & Characteristic & Frequency \\
\hline \multirow{6}{*}{$\begin{array}{c}\text { History of another skin } \\
\text { disease }\end{array}$} & Psoriasis & 3 \\
\hline & vitiligo & 3 \\
\hline & Alopecia areata & 7 \\
\hline & Alopecia androgenic & 3 \\
\hline & Eczema & 5 \\
\hline & Rosacea & 3 \\
\hline \multirow{7}{*}{$\begin{array}{l}\text { History of another } \\
\text { disease }\end{array}$} & Hypothyroidism & 10 \\
\hline & Diabetes melllitus & 8 \\
\hline & Lupus Erythematosus & 2 \\
\hline & Rheumatism arthritis & 1 \\
\hline & Behcet's disease & 1 \\
\hline & Epilepsy & 1 \\
\hline & Minor thalassemia & 2 \\
\hline \multirow{7}{*}{ Symptom } & Itching & 69 \\
\hline & Local pain & 6 \\
\hline & Tenderness & 18 \\
\hline & Local irritation & 14 \\
\hline & Hair loss & 89 \\
\hline & Red spots & 11 \\
\hline & Welding & 5 \\
\hline \multirow{6}{*}{ Sign } & Alopecia & 91 \\
\hline & scar & 25 \\
\hline & Erythema & 59 \\
\hline & pigmentation & 22 \\
\hline & scaling & 25 \\
\hline & Frontal fibrosis & 9 \\
\hline \multirow{4}{*}{ LP in other organ } & Nail & 10 \\
\hline & oral & 22 \\
\hline & skin & 58 \\
\hline & genital & 10 \\
\hline \multirow[t]{3}{*}{ Type of treatment } & Topical & 77 \\
\hline & Systemic & 85 \\
\hline & Intralesional injection & 47 \\
\hline \multirow[t]{3}{*}{ Disease features } & First LP then LPP & 29 \\
\hline & First LPP then LP & 10 \\
\hline & Only LPP & 57 \\
\hline \multirow{6}{*}{ Drug history } & Dental Gold & 0 \\
\hline & Amalgam in dental & 70 \\
\hline & Hair color & 51 \\
\hline & NSAID & 8 \\
\hline & propranolol & 8 \\
\hline & Levothyroxine & 10 \\
\hline
\end{tabular}


Moreover, table 3 shows the frequency of characteristics related to the histopathology studies.

Table 3. Histopathology report

\begin{tabular}{|l|c|}
\hline \multicolumn{1}{|c|}{ Characteristic } & Frequency \\
\hline Hyperkeratosis,follicular plugs and degeneration of basal layer & 25 \\
\hline pigment incontinence in dermis & 33 \\
\hline Degeneration of basal layer of follicular structure & 98 \\
\hline Decreased density of hair folliculs/Increased in catagen-telogen & 87 \\
\hline Perifollicular fibrosis and inflammatory cells and atrophy of pilosebaceous stuctures & 97 \\
\hline Fibrous-tract and stellae & 67 \\
\hline
\end{tabular}

A

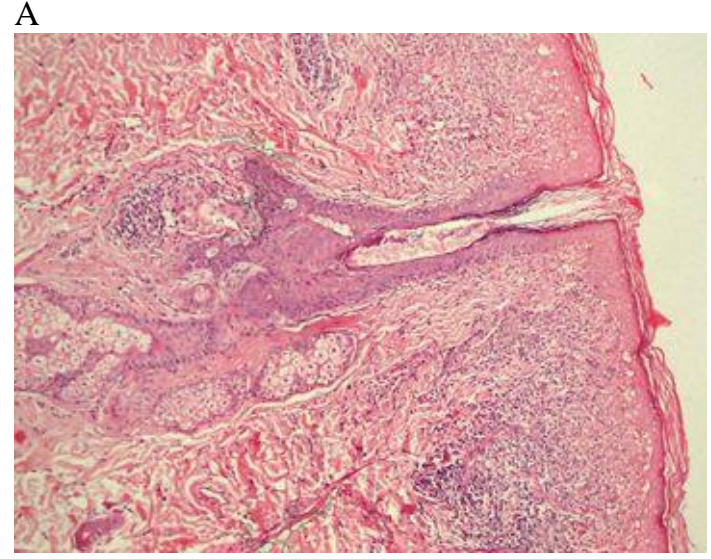

$\mathrm{C}$

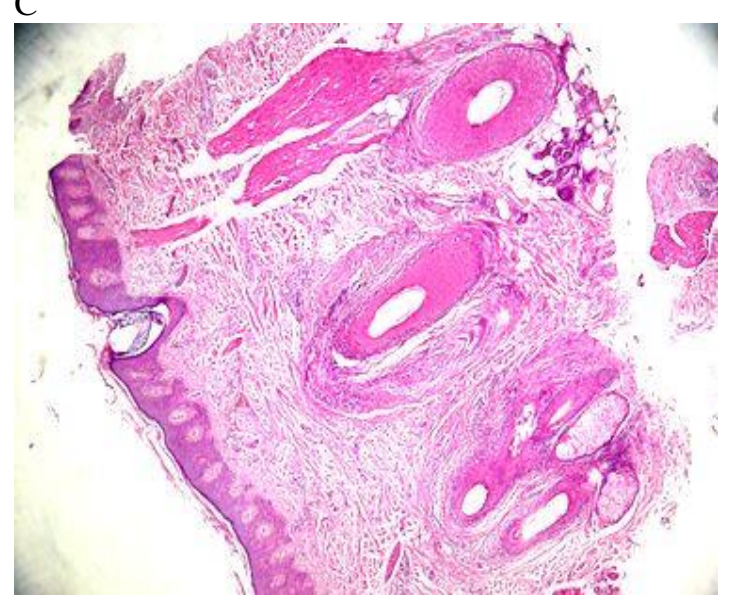

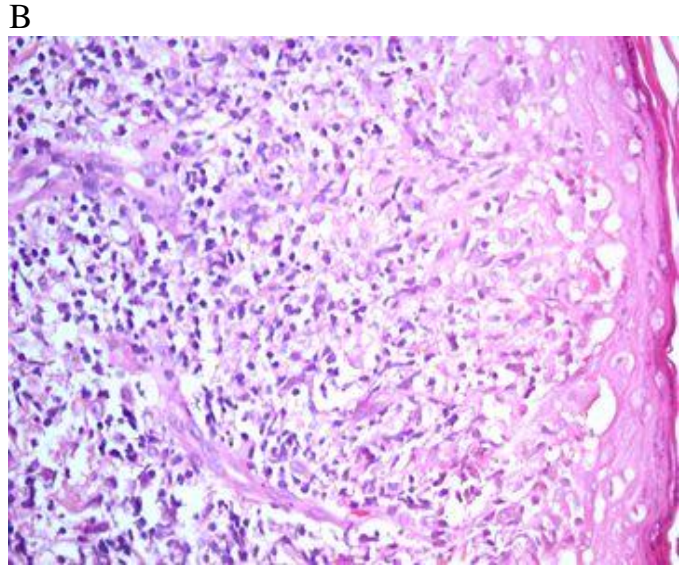

$\mathrm{D}$

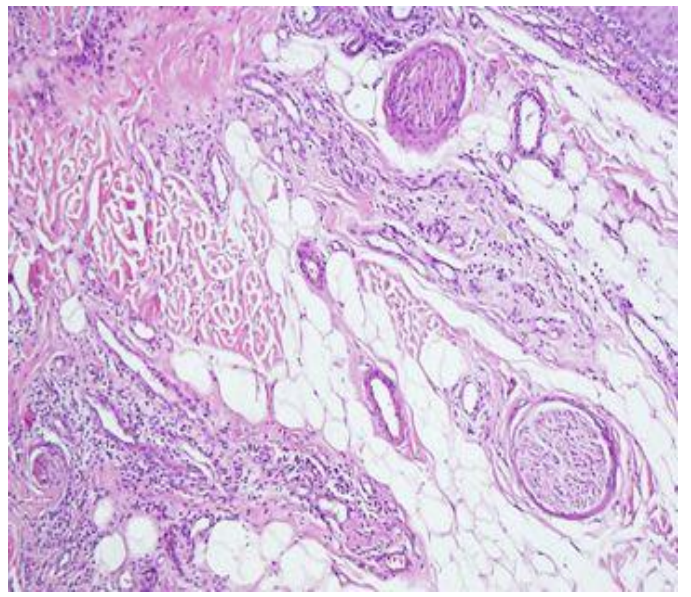

Figure 1. Histologic finding. haematoxylin and eosin (H\&E) staining and optical microscope. A, B: interface Lichenoid infiltrate with epidermal atrophy Orthokeratosis, Follicular plugs and vacuolization of basal layer -there is perivascular and perifollicular lymphohistiocytic infiltration.LPP with epidermal involvement. C, D: Normal epidermis -Lichenoid reaction pattern involving the follicular epithelium with an association of perifollicular fibrosis and lymphocytic infiltration. Area loss of hair follicle, replaced by linear tract of fibrosis in deep dermis and fat tissue. LPP without epidermal involvement

\section{Discussion}

This current, cross-sectional study attempts to explain the demographics and Clinical Features of Lichen planopilaris in the Iranian population. 
This study was compared to the results of similar studies, which discovered that usually young women are affected by LPP. These other studies demonstrated that LPP is a rare and uncommon inflammatory disease, which the results of this current study have also demonstrated within the Iranian population. Although the age spectrum for the LPP affected patients varied widely [11]: the ages of the patients participating in this study are between 14 and 82 years old. In the other studies, the range of ages for the LPP affected patients vary between 25 and 70 years old [12].

Both the age spectrum range and distribution in the Iranian population are very wide. In a retrospective study of 355 patients, where the mean age was 56 years old, the patients were between the ages of 21 to 81 [13]. In both this current study and other similar ones, Lichen planopilaris develops in association with lichen planus affecting the nails, skin, and mucosa, demonstrating similar results as the previously conducted studies [14, 15]. In the results of Mehregan et al.'s study, 45 patients, affected by Lichen planopilaris with an average age of onset of 52 years [16], participated. However, the average age of onset in this present study is 41 years.

The 10-year difference in the average age of onset of LPP for the Iranian population compared to the worldwide statistics is a very important factor which needs to be taken into consideration. In Mehregan et al.'s study, the female to male ratio was 4:1, which is similar to the ratio of the present study [16].

In Tan et al.'s study, the gender difference ratio among 25 of the patients with Lichen planopilaris was 1.8:1 [17]. In several studies, thyroid disease was significantly more frequent among the patients with Lichen planopilaris [4]. Hypothyroidism was the most common thyroid abnormality in LPP in this study, which is the same as the other studies [4]. In this study Diabetes mellitus was also common.

\section{Conclusions}

Due to the low prevalence of LPP among those included in this study, demographic and background information about the patients was collected, and their association with the disease was investigated. It is strongly recommended that further studies on the risk factors for patients newly diagnosed with LPP be done by academic referral centers.

This is also a case control study for patients whose information is in the database of the Skin Research Center, which conducts focused studies on LPP. This study has proven that the demographic criteria among the Iranian population are different, and in some cases early attention is urgent. The differences between the demographic factors can provide further studies and support, but more management models are recommended.

\section{ACKNOWLEDGEMENTS}

The authors would like to thank Dr. Azita Khiltash, M.D. for her really constructive guidance and helps.

\section{REFERENCES}

[1] Ochoa BE, King LE Jr, Price VH. Lichen planopilaris: Annual incidence in four hair referral centers in the United States. J Am Acad Dermatol 2008; 58:352.

[2] Vañó-Galván S, Molina-Ruiz AM, Serrano-Falcón C, et al. Frontal fibrosing alopecia: a multicenter review of 355 patients. J Am Acad Dermatol 2014; 70:670. 
[3] Tan KT, Messenger AG. Frontal fibrosing alopecia: clinical presentations and prognosis. Br J Dermatol 2009; 160:75.

[4] Atanaskova Mesinkovska N, Brankov N, Piliang M, et al. Association of lichen planopilaris with thyroid disease: a retrospective case-control study. J Am Acad Dermatol 2014; 70:889.

[5] Mobini N, Tam S, Kamino H. Possible role of the bulge region in the pathogenesis of inflammatory scarring alopecia: lichen planopilaris as the prototype. J Cutan Pathol 2005; 32:675.

[6] Assouly P, Reygagne P. Lichen planopilaris: update on diagnosis and treatment. Semin Cutan Med Surg 2009; 28:3.

[7] Tosti A, Piraccini BM, Iorizzo M, Misciali C. Frontal fibrosing alopecia in postmenopausal women. J Am Acad Dermatol 2005; 52:55.

[8] Matta M, Kibbi AG, Khattar J, et al. Lichen planopilaris: a clinicopathologic study. J Am Acad Dermatol 1990; 22:594.

[9] Giménez-García R, Lázaro-Cantalejo TE, Sánchez-Ramón S, Velasco Fernandez C. Linear lichen planopilaris of the face. J Eur Acad Dermatol Venereol 2005; 19:770.

[10] Duque-Estrada B, Tamler C, Sodré CT, et al. Dermoscopy patterns of cicatricial alopecia resulting from discoid lupus erythematosus and lichen planopilaris. An Bras Dermatol 2010; 85:179.

[11] Ioffreda MD. Inflammatory diseases of hair follicles, sweat glands, and cartilage. In: Lever's Histopathology of the Skin, 10th ed, Elder DE (Ed), Lippincott Williams \& Wilkins, Philadelphia 2009. p.459.

[12] Rácz E, Gho C, Moorman PW, et al. Treatment of frontal fibrosing alopecia and lichen planopilaris: a systematic review. J Eur Acad Dermatol Venereol 2013; 27:1461.

[13] Chiang C, Sah D, Cho BK, et al. Hydroxychloroquine and lichen planopilaris: efficacy and introduction of Lichen Planopilaris Activity Index scoring system. J Am Acad Dermatol 2010; 62:387.

[14] Spencer LA, Hawryluk EB, English JC 3rd. Lichen planopilaris: retrospective study and stepwise therapeutic approach. Arch Dermatol 2009; 145:333.

[15] Baibergenova A, Walsh S. Use of pioglitazone in patients with lichen planopilaris. J Cutan Med Surg 2012; 16:97.

[16] Mehregan DA, Van Hale HM, Muller SA. Lichen planopilaris: clinical and pathologic study of fortyfive patients. J Am Acad Dermatol 1992; 27:935.

[17] Tan E, Martinka M, Ball N, Shapiro J. Primary cicatricial alopecias: clinicopathology of 112 cases. J Am Acad Dermatol 2004; 50:25. 


\section{AUTHORS}

Maryamsadat Nejadghaderi is a medical doctor (M.D.) from Tehran University of Medical Sciences, Iran.

Ashkan Tashk is a Ph.D. of Electrical engineering and is currently working as a postdoc researcher at SDU in .
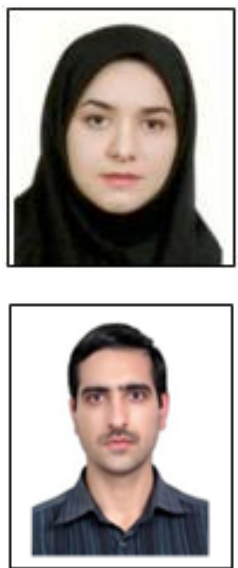

Parvin Mansouri (M.D. Professor) is currently working as a Professor of Dermatology in Tehran University of Medical Sciences, Iran.

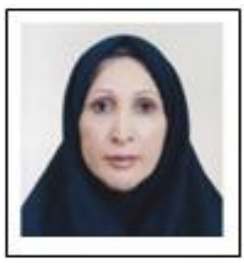

Zahra Safaei Naraghi is currently working as a Fellow in Dermatopathology in RaziSkin-Hospital, Tehran University of Medical Sciences, Iran.

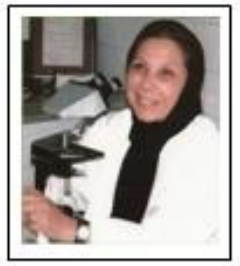

(C) 2020 By AIRCC Publishing Corporation. This article is published under the Creative Commons Attribution (CC BY) license. 